Library Acquisitions: Practice \& Theory, Volume 20, issue 1 (Spring, 1996), p. 9-21.

ISSN: 0364-6408

doi:10.1016/0364-6408(95)00076-3

Copyright (C) 1996 Published by Elsevier Science Ltd.

SSDI 0364-6408(95)00076-3

\title{
PROMPTCAT ISSUES FOR ACQUISITIONS: QUALITY REVIEW, COST ANALYSIS AND WORKFLOW IMPLICATIONS
}

\author{
MARY M. RIDER \\ Head of Copy Cataloging \\ The Ohio State University Libraries \\ 040S Main Library \\ 1858 Neil Avenue Mall \\ Columbus, $\mathrm{OH} 43210$ \\ MARSHA HAMILTON \\ Head of Monograph Acquisitions \\ The Ohio State University Libraries \\ 036 Main Library \\ 1858 Neil Avenue Mall \\ Columbus, $\mathrm{OH} 43210$
}

\begin{abstract}
PromptCat is a new service offered by OCLC, in conjunction with monograph materials vendors, that provides libraries with a full bibliographic record from the OCLC Online Union Catalog (OLUC) simultaneous to the supply of materials from a vendor. The library's holdings are set automatically on the OLUC record. Because PromptCat eliminates the need for libraries to do individual title-by-title searching and record selection when materials are received, it will streamline local cataloging activities. It may also provide an impetus for libraries to reevaluate local editing practices and determine whether materials can be processed quickly upon receipt in acquisitions rather than in copy cataloging.

This article addresses issues relating to PromptCat, including tests of the service conducted at The Ohio State University (OSU) and Michigan State University (MSU), an estimated cost/benefit analysis based on OSU's approval plan, and issues including coordination between OCLC, materials vendors, system vendors, and the library as well as workflow, organizational implications and staffing issues.
\end{abstract}

\section{INTRODUCTION}

In recent years, libraries have shown increasing interest in relying on outside vendors to supply all or part of their cataloging services. In the 1990's, economic constraints have forced many libraries to reduce staff, particularly in large cataloging departments. As a result, many libraries have concluded that they can no longer achieve desired productivity and quality standards and also maintain reasonable costs by cataloging in-house. A few libraries have outsourced cataloging entirely, but many feel uncomfortable with the loss of flexibility and diminished local expertise which this may entail. A hybrid option is to receive cataloging copy that can still be reviewed and adjusted as desired for the local system.

In this environment, OCLC announced plans for PromptCat, a service released in spring 1995 that allows libraries to receive MARC records from the OCLC Online Union Catalog (OLUC) at the same time they receive monographs from approval plan and firm order vendors. Initially, OCLC plans to offer the service in conjunction with four approval plan vendors: Academic Books, Baker \& Taylor, Blackwell North America, and Yankee Book Peddler. Other vendors will be added 
as the service expands [1]. Although PromptCat is intended for both firm order and approval monographs, this analysis will focus on approval materials only.

PromptCat operates in the following way. OCLC receives weekly updates of new titles added to the vendor's inventory. These titles are searched against the Online Union Catalog (OLUC) to locate matching bibliographic records. The bibliographic record is selected according to several match algorithms that use multiple elements to compare the vendor record to the OLUC record. At regular intervals, the vendor sends OCLC a manifest with a list of the titles to be shipped to the library on approval or firm order. OCLC supplies the matching bibliographic record to the library and sets the library's holding symbol on the OLUC record. Libraries will have various options regarding type, bibliographic level, and format of records selected, method of record delivery, and timing of the set of holdings. A Cataloging Report will be supplied for records not delivered if no matching records are found, for duplicate holdings in case the library's symbol is already attached to the selected OLUC record, and for records delivered.

Based on preference or local practice, libraries may specify which categories of copy they want to receive, e.g., DLC, CIP, member, UKM, or a combination. Records will be supplied to the local catalog using one of four delivery options. They can be provided on 1600 or 6250 bpi magnetic tapes, via Electronic Data Exchange (EDX), which is OCLC's implementation of FTP, through an online PRISM PromptCat file, or on catalog cards. Holdings may be set immediately or with a built-in 21-day delay to allow for review and processing of approval titles. If approval titles are returned to the vendor by the library, holdings may be removed from the OLUC record manually on PRISM, via EDX, by magnetic tape or MICROCON Delete.

\section{THE PROMPTCAT TEST AT MICHIGAN STATE UNIVERSITY}

Two libraries participated with OCLC in conducting tests of the prototype PromptCat service: Michigan State University Libraries (MSU) in October-December 1993 and The Ohio State University Libraries (OSU) in January-March 1994. The MSU test was performed with approval records supplied by Yankee Book Peddler. Yankee selected books for MSU's weekly approval shipment and sent bibliographic data via FTP to OCLC. OCLC searched the titles against the OLUC and set MSU's holdings on those records. A tape of the records was generated and shipped to MSU's Computer Center [2].

A major question in both tests was whether OCLC's matching algorithm would locate the correct bibliographic record based on the vendor-supplied data. Another concern was whether OCLC would select what libraries considered the best available record in the OLUC and whether the copy would be suitable for the local catalog.

In her review of the test at MSU, Kay Granskog indicated that the percentage of matching records supplied by OCLC was $99.4 \%$ [3]. She also indicated that $40 \%$ of the records supplied were full-level Library of Congress records that required no revision. Since MSU performed some "straightforward cataloging" in acquisitions, they were able to process many of the PromptCat records in this same manner. Acquisition staff matched the PromptCat record against the book in hand, input the location code, and wrote the call number in the book. Since access points are reviewed later by an outside vendor, headings were not verified. Call numbers were not adjusted if they fit certain criteria. Because MSU does not consider this process full copy editing, they describe it instead as "monographic check-in," and have developed the following criteria for "check-in" of books in the Acquisition Department:

1. Author, title, edition, imprint, and date on record match the book in hand; 
2. Bib Lv1 $=m$ and Enc Lvl $=($ blank $)$ or $\mathrm{I}$;

3. Call number $(050 / 090)$ is present and not in class M, ML, MT, P-PZ, Z [These classes require cutter number adjustment.];

4. Title is not an analytic, LAW title, a set, an added edition, or an added conference proceedings [4].

One of the problems raised by the test at MSU was how to distinguish newly-loaded PromptCat records from records for fully-processed materials available for public use. In the MSU test, it took approximately $21 / 2$ to 3 weeks to complete shelf processing of titles in the PromptCat sample. These titles already showed MSU's holdings in OCLC and in the local catalog. Because of concern that these titles would generate interlibrary loan activity, acquisition personnel forwarded rejected approval titles immediately to the database management area to remove MSU's holdings from the OCLC record and the online catalog. This was particularly important because there was no indication in the public catalog that PromptCat titles were not available on the shelf. Because of the speed with which PromptCat bibliographic records are supplied, each library will need to decide whether OCLC holdings should be set immediately or delayed and whether a note or status code should be added to records in the local system to alert users that titles may not be available for circulation.

MSU considered the test of the early product to be "a good compromise between totally outsourcing a workflow that represents a high volume of material and full in-house processing. By stamping and labelling books ourselves the library retains the right to return an unmarked book to the approval vendor. The library gains the possibility of faster processing but still receives the books from the vendor immediately after they are profiled" [5].

\section{THE PROMPTCAT TEST AT THE OHIO STATE UNIVERSITY}

The second PromptCat test was performed at The Ohio State University Libraries with the Baker and Taylor Company (B\&T). The OSU Libraries (OSUL) receives approximately 18,000 approval titles annually from B\&T. Normally, abbreviated MARC bibliographic records are provided by B\&T on tape shortly before receipt of the weekly approval shipment. Each title is searched in Monograph Acquisitions against the local catalog (OSCAR, an INNOPAC system) to identify duplicates, added volumes, added editions, analytics, series on standing order, series or serials cataloged as monographs, etc. Books are then displayed for 1 week for collection managers who decide whether items should be selected or rejected. Acquisition staff complete processing of the local order record and forward all selected books to the cataloging department where tides are searched to locate suitable OCLC copy. The copy chosen for cataloging will eventually overlay the brief record supplied by the vendor. Although several vendors, including B\&T, are capable of providing cataloging copy using the LC MARC tape service, until now there has been no mechanism to obtain the unique OCLC number on vendor-supplied records or to automatically upload the library's holding symbol to OCLC. For libraries like OSU that have a commitment to contribute to the OCLC database, this was a problem. PromptCat does fulfill these two needs. Since PromptCat will supply the local system with an OCLC record at the point of a book's receipt, it will also make it possible for OSU to finish processing in acquisitions rather than send all books to the cataloging department for search and copy editing.

The test at OSU examined whether the record selected by the PromptCat service would match the record selected in cataloging. Based on a random sample of 200 books, 182 records (91\%) 
matched one-to-one with those chosen by OSU. For the remaining 18 titles (9\%), two records were supplied by OCLC, one of which matched OSU's choice. Multiple records were supplied for OSU personnel to test and evaluate the OCLC searching algorithm. In all but one case, the record with the highest match rate was also the preferred OSU record. In the final product, only one record will be supplied according to the matching algorithm.

The search algorithm was also evaluated in a second non-random sample of 128 problematic titles flagged by OCLC for special review. Of this group, OCLC supplied one record for 108 records $(84 \%)$ that matched those chosen by OSU internally, multiple records for 10 tides $(8 \%)$, one of which matched OSU's choice, and 10 records $(8 \%)$ that did not match the record selected by OSU. Again, these were considered problematic titles. The 10 records that did not match OSU's choice also included records where OSU decided on a different cataloging treatment (e.g., multivolume set vs. individual monograph) than the one for which matching copy was found in the OLUC.

As a result of these two tests, the Library gained confidence that OCLC's record selection (based on the match algorithm and other criteria) could replicate OSU's own decision process in selecting cataloging copy $91-99 \%$ of the time. Because acquisition staff search approval titles in the local system prior to retention review, local cataloging practice that may differ from PromptCat copy can easily be identified without additional searching.

A second issue addressed in the OSU test was the quality of records supplied by PromptCat. In this case, the speed with which OCLC supplied copy meant that a higher than usual proportion of CIP records were delivered. Sixty-five percent of the test records were CIP, 25\% were DLC (Library of Congress), $8 \%$ were OCLC member copy, and 2\% were UKM (UK MARC). Currently, OSU approval titles are cataloged about 3 to 4 weeks after receipt. By the time OSU cataloged the sample of 182 titles, 49 CIP records (or 42\%) had been upgraded to DLC blank or 1 encoding level copy.

This raised the question of whether it would be advantageous to wait several weeks after receipt of books for PromptCat CIP records to be upgraded to full-level DLC copy or to have OSU staff upgrade the CIP records to make materials available for patrons.

To help answer this question, the amount of editing that would have to be done to integrate CIP copy into the local catalog was evaluated. For the sample of 182 titles, $78 \%$ of the CIP records required adjustment to fields other than call number, but the average number of changes per records was relatively low, an average of two fields per record. These changes were mostly in the 300 description field (pagination, size) and 260 publisher field (including date of publication) and would have to be added or revised on most CIP copy. The evaluation helped to convince the OSU Libraries that it would be relatively simple to revise CIP records at the point of receipt and that it would better serve patrons to upgrade CIP PromptCat records when the books were processed in acquisitions rather than delay processing. This would provide materials 2-3 weeks faster than the current workflow.

The tests conducted at MSU and OSU showed that the selection of PromptCat records using the OCLC matching algorithm was highly accurate. This prompt delivery of records also reinforced the idea that libraries will realize a greater benefit from PromptCat if they are willing to accept OCLC-supplied copy with a minimum of local adjustment [6].

\section{COST/BENEFIT ANALYSIS}

A preliminary estimate of PromptCat costs associated with the OSU Baker \& Taylor approval plan indicates that the service will be cost-effective, particularly when compared with average 
figures for in-house processing that include direct OCLC charges (e.g., search for copy, FTU's for uploading holdings) as well as indirect charges for staff time and salaries. The total cost of PromptCat will vary somewhat for each library depending upon the method chosen for delivery of records (e.g., tape, EDX, cards or PRISM PromptCat file) and removal of holdings for rejected approval titles. OHIONET has announced that the 1995/96 PromptCat charge will be $\$ 1.925$ per record. This per record charge will occur regardless of whether the record is retained in the local system. Libraries with a low approval rejection rate, thus, will realize greater savings.

In addition, there will be an initial set-up fee of $\$ 220.00$ profiling charge per vendor. A library may be assessed charges for the EDX annual fee (Electronic MARC annual fee of \$198.00) and electronic MARC monthly processing charges of $\$ 22.00$ if that is the delivery mechanism chosen. If records are placed in a PRISM PromptCat file, the library will be charged regular export charges of $\$ .1045$ per record when the record is downloaded [7].

To estimate annual, direct costs for the PromptCat service at OSUL, excluding profiling charges, the $\$ 1.925$ per record delivery charge was multipled by 18000 which is the average number of Baker \& Taylor approval titles received yearly [8]. If OSU were to receive PromptCat records via tape for approval books, the annual cost of those tapes (\$16.50 each for 52 weekly 1600 bpi tapes) would be $\$ 858.00$ (see Table 1).

OSU will investigate the feasibility of electronic transmission of PromptCat data, but since tapes are the current delivery mechanism used for approval records, tapes were used for this cost/benefit analysis.

The cost per record for using the PromptCat service can be estimated on the basis of the average number of B\&T approval records received annually (ca. 18,000) minus an average return rate

TABLE 1 Estimated Cost of PromptCat Service for OSUL B\&T Plan

\begin{tabular}{ll}
$\$ 34,650,00$ & $\begin{array}{c}\text { Record charge of } \$ 1.925 / \text { record } \times \text { ca. 18,000 B\&T approval titles received annually } \\
\text { (includes titles retumed to B\&T) } \\
\text { Weekly (52) l600 bpi tapes at } \$ 16.50 \text { each (B\&T ships } 52 \text { times per year) }\end{array}$ \\
\hline 858.00 & $\begin{array}{l}\text { Total estimated annual cost of PromptCat B\&T approval service } \\
\$ 35,508.00\end{array}$ \\
\hline
\end{tabular}

of $6 \%$ (ca. 1,200 books were returned to the vendor last fiscal year). This is a rough estimate that assumes PromptCat would supply catalog records for all of the remaining 16,800 approval titles annually (see Table 2).

We know, however, that a small percentage of records will not have matching or acceptable OCLC copy. In a few cases, OSU may not use the PromptCat-supplied record if it does not reflect the Libraries' preferred cataloging treatment (e.g., monograph copy supplied for title cataloged at OSU as serial or monographic set), but these numbers should not significantly affect the average per record charge.

For an average of $\$ 2.11$ per title (excluding set-up charges), OCLC will supply a matching bibliographic record for approval tides and set OSU holdings in the OLUC. Other processing activity will continue to be performed in-house. In addition to processing the record for retention and payment, OSU staff will need to add some data for the local catalog including library location codes, material and record type, circulation status, and barcode numbers. OSU personnel will need 
to complete descriptive information that may be lacking on CIP copy (estimated to be $65 \%$ of the PromptCat records), and accept with minor revisions DLC (25\%) and member copy (8\%). Due to different national standards, UKM copy (2\%) may require more extensive checking and revision by cataloging staff.

It is hoped that in the majority of cases, OSUL will be able to process books and records quickly after they are reviewed for retention in acquisitions. In order to achieve this goal at the OSU Libraries, local editing policies and practices are being reviewed to change workflows so that some records can be completed in acquisitions without having to go to a separate cataloging area.

This means that it will be possible to have books on the shelf and available for circulation an estimated 2-3 weeks earlier than is presently the case. Catalog records will also be displayed more quickly in the local system while books are in process. This will facilitate review by collection managers and reduce potential duplication in preorder search for firm ordered titles. The option will be available in the local system to display records for staff and suppress them from public view until books are completely processed.

To further evaluate how the estimated costs for PromptCat compare with traditional costs for OCLC search and copy cataloging activities, OSUL looked at both direct OCLC charges as well as the average number of titles cataloged per hour at OSUL and the number of FTE staff needed to search and edit approximately 16,800 books annually. Presently, OCLC charges for online search and update of holdings in the OLUC via OHIONET amount to direct costs of $\$ .79$ per record. Average direct costs for cataloging 16,800 titles would, therefore, amount to $\$ 13,272$ annually (see Table 3).

TABLE 2 Estimated Per Record Cost of PromptCat

\begin{tabular}{|c|c|}
\hline \multicolumn{2}{|c|}{ Number of B\&T Titles: } \\
\hline 18,000 & Average number of $B \& T$ titles received annually \\
\hline 1,200 & Average number of $B \& T$ books returned to vendor (based on average return rate of $6 \%$ ) \\
\hline 16,800 & Catalog copy used for B\&T books (after returns) \\
\hline \multicolumn{2}{|c|}{ Estimated PromptCat costs: } \\
\hline$\$ 35,508.00$ & Total cost of PromptCat copy supplied; copy used for 16,800 titles \\
\hline$\$ \quad 2.11$ & Per title cost of PromptCat copy, factoring in returns, record and tape charges \\
\hline
\end{tabular}

TABLE 3 Estimated OCLC Costs for B\&T Approval Books

\begin{tabular}{lll}
\hline$\$$ & .34 & Per record OCLC search for copy \\
$\$$ & .45 & Per record FTU (First Time Use) to add library's holding symbol in OLUC \\
$\$$ & .79 & Total per record OCLC charge to search/update holdings \\
\cline { 1 - 1 }$\$ 13,272.00$ & & Total annual OCLC online charges for cataloging $(\$ .79 \times 16,800$ B\&T approval books) \\
\hline
\end{tabular}

While the direct costs of in-house search and cataloging per title are low, less than $\$ 1.00$, other factors, including divided workflows, sorting and moving materials, and staff time spent editing records for local practice, etc. increase costs substantially. At OSUL, an average of about 3 titles per hour can be searched and edited, even though search for copy is currently handled separately from copy cataloging for most materials. At this rate, assuming that a staff member edits records 
for 7 hours per day, a total of 21 titles/day/person can be processed. Although there are 260 work days in the year, OSU recognizes 11 official holidays. Civil service staff also receive from 2-5 weeks vacation, depending on years of service [9]. Using a figure of 3 weeks vacation per year plus holidays (234 working days/year $\times 21$ titles/day) approximately 4,914 titles can be searched and edited annually per FTE staff. It would therefore require 3.4 FTE to search and edit the 16,800 B\&T approval books selected annually based on current OSU procedures and editing practices. Based on an average salary of $\$ 21,500$, plus the university's estimate of benefits equal to $22 \%$ of the base salary, the total cost of hiring 3.4 staff members comes to $\$ 89,182$ [10]. If the annual cost of weekly OCLC tapes to load records to the local system is added to staff salaries, in addition to direct OCLC online charges, the annual cost of cataloging 16,800 approval titles amounts to $\$ 104,456$ annually or $\$ 6.22$ per title (see Table 4). This is a conservative estimate because it does not factor in staff overhead such as sick leave, other assignments including committees or meetings, and other library duties. It also does not include additional database charges for authority processing which is handled separately at OSUL [11].

Staff costs for completing PromptCat records in acquisitions are difficult to estimate because this process was not actually performed during the OSU test. However, using time study estimates based on the assumption that a percentage of PromptCat copy will be processed with minimal editing, it may be possible for a staff member to process 8 titles per hour (see "Determine Staffing Needs" later in this article) This includes current acquisition check-in (3 minutes/title) plus review and completion of the catalog record (4 minutes/title). At this rate, it is estimated that 1.2 FTE would be needed to check-in and complete processing for 16,800 approval titles. Using the same average salary plus benefits figure used above, $\$ 31,476.00(\$ 26,230.00 \times 1.2 \mathrm{FTE})$, plus the estimate of OSU's annual PromptCat service $(\$ 35,508)$, the cost of processing 16,800 approval titles using PromptCat would be $\$ 3.99$ per title. This figure is calculated differently than the cost of search and copy cataloging (\$6.22/title) because it includes staff time for acquisition check-in, but also assumes, for the sake of comparison, that all titles would be processed in acquisitions, even though it is estimated that up to $20 \%$ of records would still be forwarded to cataloging, again increasing the total cost per title. This $20 \%$ reflects an estimate of titles classed in P, M, and N as well as miscellaneous serial, analytic and special collections titles that require call number adjustment or special processing.

Based on the above estimates, it appears that PromptCat is a cost-effective service. Compared to current costs for search and copy cataloging ( $\$ 6.22 /$ title), if all 16,800 records could be processed at the rate of $\$ 3.99 /$ title, the library would realize a $35 \%$ savings for processing of approval titles, with no significant differential in quality [12]. While promising, it does appear that the degree to which PromptCat can be truly cost-effective and the extent to which it can replace or reduce OCLC search and copy editing, will depend largely on individual libraries and whether they can minimize in-house editing after books are reviewed and selected. These "hidden" factors can quickly escalate per title processing costs. 
TABLE 4 Estimated OSUL Costs for Search and Copy Cataloging

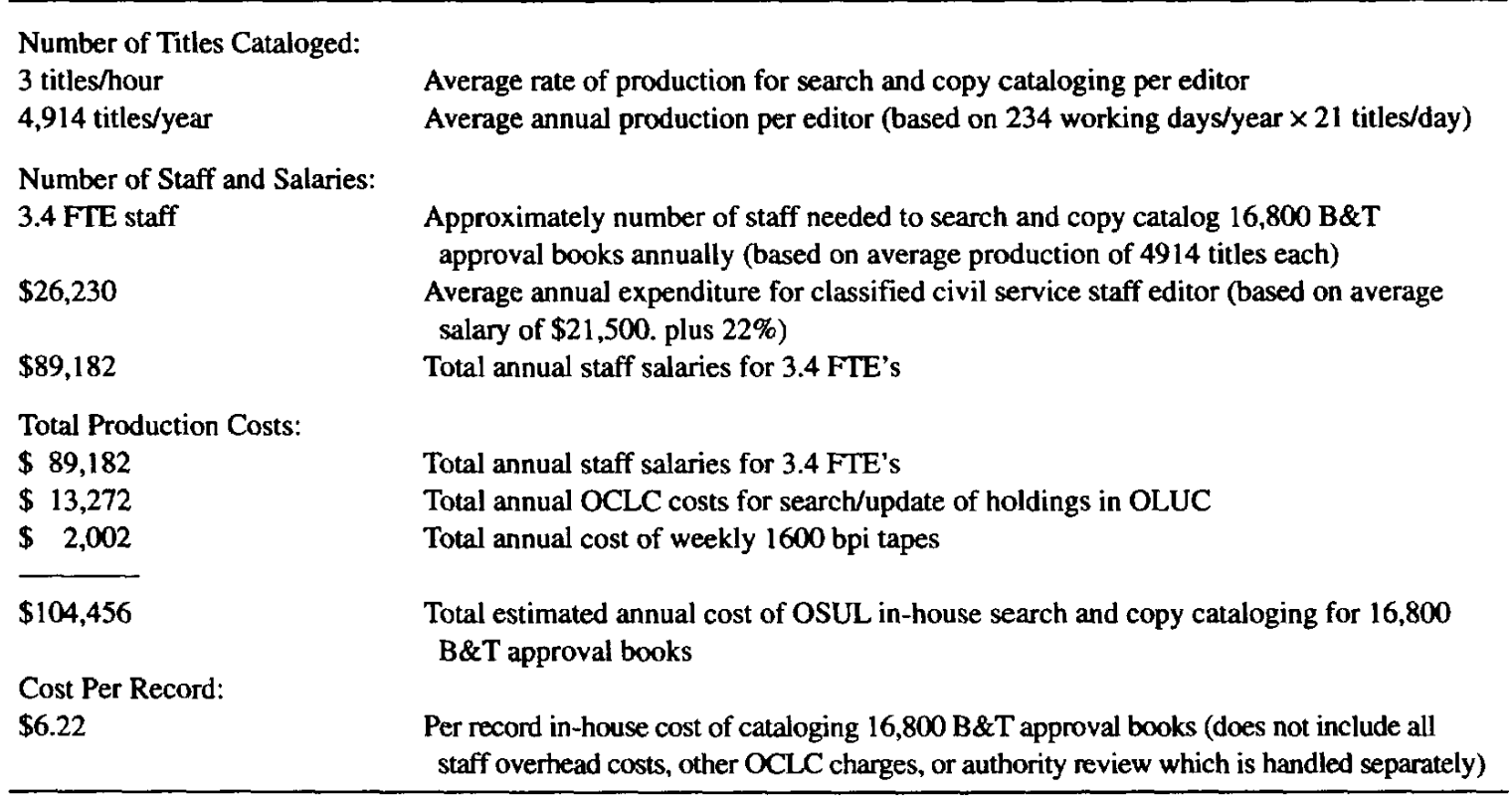

\section{WORKFLOW ISSUES}

In general, smaller libraries traditionally have had an advantage in being able to process incoming materials quickly because items do not have to move from place to place or person to person, sit in backlogs, or have the same record worked on at different times. Libraries with a larger number of incoming receipts are more likely to have separate units to handle different functions. The same item is passed from person to person in an assembly line process. Historically, this arrangement developed to allow large libraries, which also had large personnel budgets in the past, to take advantage of staff who were trained to handle specific tasks. For example, acquisition receipt, search for OCLC copy, copy cataloging, and even labeling could be handled in separate units or departments on the theory that this arrangement would maximize expertise on the part of staff performing a narrowly-defined function.

While PromptCat does not require libraries to change workflows or handle materials differently, it does provide a powerful impetus, particularly for larger libraries, to reevaluate existing practices and organizational schemes to maximize PromptCat's benefits. Because PromptCat provides a full OCLC catalog record at the point of a book's receipt, it enables acquisition and copy cataloging functions to be handled at the same time as part of a unified process. The merging of acquisition and cataloging activities has been practiced in recent years in libraries that have instituted "fastcat" processing so that monographs can be "checked in" and records added to local catalogs without extensive review or revision of existing copy. Michigan State, among other libraries, already had experience with this method of monographic "check-in" when they tested the prototype PromptCat service in late 1993. However, even if OCLC records were downloaded to the local system at the time of firm order, staff still had to search OCLC for approval titles. It is this step - the OCLC search for acceptable catalog copy and setting of holdings for approval titles - that PromptCat will eliminate. The library is left with editing records for the local catalog only and shelf preparation of the physical piece. By handling receipt and cataloging at the same time, all information gained during check-in or problem-solving would remain with one individual, and not be subject to loss as 
the item is passed from unit to unit. Approvals with no copy or unacceptable copy could continue to be forwarded to a copy and/or original cataloging unit to handle problems, such as call number assignment, that would otherwise slow approval processing. This would speed the shelf-readiness of a larger percentage of newly acquired materials and hypothetically free copy editors to focus on more problematic titles. It also means that there are fewer opportunities for books to be misplaced or errors made as items are transferred from one work area to another.

\section{IMPLEMENTING PROMPTCAT IN TECHNICAL SERVICES}

Libraries interested in using PromptCat will want to do some planning in advance to ensure that local system requirements and library needs are compatible with the various options offered by the service. Although the service does appear to offer a cost-effective alternative to local OCLC searching and may reduce editing of catalog copy, libraries will want to evaluate it based on their specific needs and objectives. In planning for implementation, at least three major areas should be addressed by libraries. These include knowledge of the local system and how PromptCat records will interface in the local database, impact of the service on library workflows and staffing requirements.

\section{Know Your Local System}

Since libraries will have various options with PromptCat and can establish criteria for record selection as well as choose the method of delivery, it is important that libraries understand how PromptCat will interact with the local system. For example, OSUL currently receives brief MARC bibliographic and order record information from B\&T which is loaded via tape directly into the local INNOPAC system. Since PromptCat includes the option to pass through vendor information in 9xx MARC fields of the OCLC bib record, it will be important to review order/acquisition data and its location in the MARC record with the system vendor, B\&T and OCLC network representatives to make certain that this crucial information can be entered and read correctly by the local system. Libraries will need to take the initiative and work closely with system vendors to insure that vendor-supplied data in PromptCat records interfaces appropriately with the local online system. Coordination and additional programming may be necessary to take advantage of the options offered by PromptCat.

Because OSUL's local catalog (OSCAR) is an INNOPAC system, separate item records must be created for each physical piece and linked to appropriate bibliographic records for circulation. OSUL wants to develop the capability to create item records using a template in the local system that will allow certain default information to be provided automatically when bibliographic records are loaded. This would greatly speed up processing when books are checked-in. Again, coordination with OCLC or a network representative, the system vendor, and the library will be important during the initial set-up period.

The PromptCat delivery method chosen will have an impact on library workflow. With tape or EDX delivery of PromptCat records, the library may be able to create order records immediately for acquisition purposes but editing of bibliographic records must be done directly in the local system. This may have an impact on some libraries, including OSUL, where bibliographic records are currently edited on PRISM and tapeloaded to the local catalog. Delivery using a PromptCat PRISM file will allow records to be edited on OCLC using PRISM commands and then exported when complete to the local system. However, this means order records for acquisition processing will not be available until after the title is fully cataloged. For OSUL, this alternative is unacceptable.

Libraries should also be aware of the impact PromptCat will have on local patrons if records are available to the public in the local system before books have been processed and sent to the 
shelf. This may be a particular problem if a patron requests an approval title which a collection manager elects to return to the vendor. Libraries may want to suppress PromptCat records from public display while materials are still in process, if they have that option in the local system. Alternatively, libraries may want to load PromptCat records with an added note alerting patrons that the item has been received on approval and is not yet available for circulation. Because the OCLC holdings symbol is set at the time the record is delivered to the library (or set at a 21-day delay), interlibrary loan requests may be generated for materials that are still in process or that might be returned to the vendor. For books that are returned to the vendor, OLUC holdings will have to be removed as quickly as possible to reflect accurate holdings and to minimize interlibrary loan requests.

\section{Decide What Workflows Will Work Best for the Library}

PromptCat can be implemented adapting the library's current workflows if that is desired. In other words, if acquisition and cataloging functions are presently handled separately in different departments, materials could still be checked-in and cleared for payment in acquisitions and then forwarded to cataloging for editing. The only "real" activity that PromptCat would replace is the need to search for OCLC copy since records will be supplied. However, this minimizes the advantages PromptCat can provide. If libraries choose to develop new workflows and reduce local editing to maximize PromptCat's potential, they will need to consider whether it will be acceptable to edit some records in acquisitions rather than forwarding all items to cataloging.

Libraries can profile with OCLC to select what types of records will be supplied via PromptCat (e.g., DLC, CIP, member, UKM). If they determine what is considered "acceptable" copy (e.g., LC call number and subjects available on record; call number does not have to be adjusted locally), these titles can be "checked in" in acquisitions. Records that do not fall within these categories could be forwarded to cataloging for more extensive revision. Since PromptCat records include a sizable percentage of CIP copy (at OSU, 65\% of test records were CIP), libraries will need to determine whether they will supply missing descriptive information in acquisitions. (At MSU, CIP records were sent to cataloging for completion during the PromptCat test. OSU is currently reviewing whether to process DLC and CIP records in acquisitions.)

Libraries can further enhance the value of PromptCat if they can accept call numbers on OCLC copy without additional adjustment for the local shelflist. At MSU, records with M, ML, MT, P-PZ, and Z call numbers were sent to cataloging; otherwise the call number on incoming copy was accepted without further adjustment. OSU has also been reviewing call number policy and recently decided that LC call numbers will no longer be adjusted to maintain alphabetic shelf list order. The exception to this will be classes $\mathrm{M}, \mathrm{N}$, and $\mathrm{P}$, which OSUL will continue to adjust in order to keep works by or about individual musicians, artists, or literary authors together on the shelf.

While each library will evaluate its needs, it appears likely that some records will be processed quickly in acquisitions and other materials will need to be forwarded to cataloging for completion of problematic records or adjustment to reflect local practice. The following outlines a proposed PromptCat workflow for the OSU Libraries that would facilitate processing in acquisitions for the majority of records with acceptable copy. 
- Vendor supplies OCLC with weekly updates of new titles added to their inventory. Titles are searched against the OLUC and matches are made.

- The vendor supplies OCLC with a manifest of titles to be supplied on approval to the library. OCLC retrieves the appropriate bibliographic records, sets holdings, and produces a Cataloging Report.

- PromptCat records are loaded into local catalog (OSCAR). Order record, item record, and online invoice are generated automatically by data in the PromptCat 9xx MARC fields and load templates in the local system [13].

- Approval books are searched against local catalog to identify pertinent information, including added volumes, duplicates, added editions, analytics, monographic series cataloged separately, etc. Search results are transcribed to approval slips placed in each title for collection manager review.

- Titles are displayed on review shelves for one week.

- Titles are pulled from shelves; INNOPAC order records are updated to show selecting location, fund, price, date of processing, etc.

- At same time, PromptCat bibliographic record is verified against book in hand; additions or corrections are made if necessary. (If record does not fall within guidelines for processing in acquisitions, the book is forwarded to a cataloging editor for completion.)

- Item record is updated for circulation data in local system, including codes for library location, material and record type, circulation status, volume or copy number, and barcode, etc.

- Book is barcoded, labelled, magnetic stripped, and prepared for shelf.

- Book is forwarded to Circulation for shelving or Mail Room for shipment to departmental libraries.

\section{Determine Staffing Needs}

After the library determines how and where PromptCat materials will be handled, they will need to consider whether current staff should be reassigned to handle PromptCat processing. Staffing needs can be estimated, based on three factors:

1. number of approval titles received/retained annually,

2. percentage of materials that can be handled in acquisitions, and

3. estimated amount of time per record needed to "check-in" vs. "catalog" materials.

It is estimated above that OSUL will catalog approximately $16,800 \mathrm{~B} \& \mathrm{~T}$ approval titles per year. Copy cataloging production averages 3 titles per hour per person, but OSUL would like to move processing for a sizable majority of the PromptCat records to the "front-end" in acquisitions even though it is not certain how many titles per hour can be handled this way. Since it currently takes approximately 3 minutes for the acquisition order record to be processed, if it takes another 4 minutes to verify that the bibliographic record matches the book in hand and to update the item record, it may be possible to "check-in" books at the rate of 7 minutes per title. This would be about 8 titles per hour, substantially higher than the current copy cataloging rate. A staff member processing 7 hours per day could complete 56 titles. At 234 working days per year, one FTE staff member could process 13,104 titles annually, which is about $78 \%$ of OSLTs annual B\&T approval receipts. Of course, these are only estimates, which may vary in practice depending upon how many records fit criteria for quick completion in acquisitions. For example, if CIP records are 
processed in acquisitions, it may take longer to revise those records. But up to $20 \%$ of records will continue to be forwarded to cataloging for certain categories including class numbers $\mathrm{M}, \mathrm{N}$, or $\mathrm{P}$, which means less time will be spent on those records in acquisitions.

The advantages of approval plans are that materials come in quickly, can be reviewed prior to purchase, and can be rejected if inappropriate for the library. Since a feature of PromptCat is to set the OCLC holdings in the Union Catalog, the library should be aware of its approval return rate when deciding to use this new product. In general, a return rate of over $10 \%$ for domestic plans is considered unacceptable; a return rate of over 5\% for foreign plans is costly due to overseas shipping and postage. If the library's return rate is high, it may be advisable to update the profile prior to implementing PromptCat. Otherwise, the deletion of holdings for rejected titles might be too costly and time-consuming. First, the holdings must be removed promptly so that interlibrary loan requests are not generated. Second, the library is paying a PromptCat fee for all copy provided, even for titles that are rejected. There is also staff processing time for rejected titles, preparation of credit memos, invoice adjustment, shipping, and postage on returns.

In these days of shrinking technical services personnel, the number of FTE staff assigned to approval processing may be limited. When moving forward the function of verifying book in hand to PromptCat copy, editing copy, and preparing the book for the shelf, it must be realized that acquisition processes may be slowed, although through-put time from beginning to end for individual titles should improve. Because payments can be delayed if approval processing is not maintained in a timely manner, the acquisition function has traditionally not had the ability to allow backlogs to develop in a manner considered more acceptable for cataloging functions. To maintain current status in acquisitions, it may be necessary to reassign personnel. Depending on the library, a forward shift of personnel from copy cataloging to PromptCat processing may be viewed as a welcome chance for cross-training, learning new skills, seeing a book through from beginning to end, and a chance to better serve patrons by providing materials more quickly. Each library has a different organizational climate and the impact on staff and librarians of the immense changes facing technical services today should not be underestimated. Librarians and staff are very aware of the consequences of outsourcing technical services processes. The number of people employed in technical services today is far less than the typical library of ten years ago [14], The psychological implications for staff and librarians of implementing vendor-based services should be addressed openly. Ideally, staff and librarians should be given the opportunity to be reassigned or cross-train for positions where their expertise is needed and required for the processing workflows of the future [15].

\section{SUMMARY}

In summary, PromptCat is another in the new line of vendor-based services being introduced to streamline technical services processes within libraries. It provides OCLC copy for titles supplied by participating approval vendors. Since OCLC bibliographic copy is provided and OCLC holdings are set at the point approval books are shipped, the library can adjust workflow to edit copy during acquisition processing. This can speed up processing materials for patrons and cut costs by minimizing the number of staff handling an item and the number of times a record must be accessed. The overall effect can be to introduce "small library" processing in a large library approval environment. PromptCat eliminates local search for copy by using an effective matching algorithm. While not eliminating the need for local editing and approval processing, PromptCat streamlines the process by providing copy containing the unique OCLC number and holdings at a price generally below that possible using local library staff. Preliminary estimates indicate that 
PromptCat may save approximately one-third of copy cataloging costs for selected approval titles. When considering the PromptCat service, the library should ideally study local cost and workflow implications. The service provides an excellent impetus to review expensive and time-consuming local practices. The library should work closely with systems and book vendors to insure the compatibility of the PromptCat service with the local online system. Psychological and staffing implications should also be considered. Many staff and librarians are concerned about job security and satisfaction in the face of increasingly sophisticated vendor-supplied services and the specter of outsourcing. Finally, the increased speed with which materials can be made available to patrons should be considered, especially if changes in workflow and local systems can be adopted to maximize the benefits that PromptCat can provide.

\section{REFERENCES}

1. Information on PromptCat was obtained from OCLC-supplied promotional literature and by OCLC project coordinators during the OSUL PromptCat test. At the time of writing, some libraries and vendors have postponed testing PromptCat due to programming needed for local systems.

2. Granskog, Kay. "PromptCat Testing at Michigan State University," Library Acquisitions: Practice \& Theory, 18 (1994), 419-420.

3. Ibid, p. 420.

4. Ibid, p. 423.

5. Ibid, p. 425.

6. The OSUL test focused on comparing PromptCat record selection and match rates to the Libraries' current search methods. The test was performed using paper reports and was not done by adding records to a "live" system. Further pro-gramming will be required before PromptCat can be integrated into the Librarie' INNOPAC system.

7. These figures are for the PromptCat service through OHIONET. Charges for libraries within other local networks and consortia may vary.

8. In FY 1994, OSU received 18,380 Baker \& Taylor approval titles.

9. Information provided by OSU Libraries Personnel office.

10. Salary and benefits based on average figures provided by the OSU Libraries Personnel and Business Offices.

11. See Dilys E. Morris, "Staff Time and Costs of Cataloging," Library Resources \& Technical Services, 36 (January 1992), 79-91, for a detailed, longitudinal study of cataloging costs conducted at Iowa State University Library in 198790. ISUL also copy cataloged an average of 3 titles/hour and factored in staff overhead and other cataloging activities for an average per title cost of $\$ 8.18$ per record over a 3-year period. It was also noted that these per title costs increased $25 \%$ over the 3-year period of the study; from $\$ 7.74$ in $87 / 88$; to $\$ 8.24$ in $88 / 89$; to $\$ 9.02$ in $89 / 90$.

12. All savings are estimates since "monograph checkin" was not tested during the OSUL PromptCat test. Additional costs for system programming to enable local implementation of PromptCat are also not covered in this article and would vary depending on the local online system and library needs.

13. This is a hypothetical workflow because the OSUL system currently does not have the capability to create bibliographic, order and item records simultaneously.

14. Homey, K. L. "Fifteen Years of Automation: Evolution of Technical Services Staffing," Library Resources \& Technical Services, 31 (Jan.-Mar. 1987), 69-76.

15. For more detailed information on the OSUL PromptCat test, see manuscript by Mary M. Rider, "PromptCat: A Projected Service for Automatic Cataloging — Results of a Study at The Ohio State University Libraries," which is forthcoming in Cataloging \& Classification Quarterly. 